\title{
Designing Effective Online Orientation Programs for First-Year University Students
}

\author{
Nicole Crozier, University of Victoria
}

While asynchronous, self-paced online orientation programs are not new to the field of orientation, transition and retention, COVID-19 forced many institutions to rapidly create such programs for the first time for fall 2020. This literature review uses the community of inquiry model as a framework to explore the research related to orientation and online learning and identify the principles, practices, and processes that can help student affairs professionals design an effective and engaging online orientation program or enhance an existing program.

Keywords: online orientation, self-paced modules, community of inquiry model, first-year students, transition, student success

Orientation programming has long been a part of supporting the transition of students from K-12 to higher education. These programs have evolved and expanded over the years as institutions have increasingly focused on student success and retention. In 2020, the field experienced a rapid period of change, as many institutions moved their orientation programming online in response to COVID-19. This literature review explores the research related to orientation and online learning to identify the principles, practices, and processes that can help student affairs professionals design an effective and engaging online orientation program.

\section{Orientation and Online Learning}

\section{An Introduction to Online Orientation}

Online orientation uses information technology, such as a website, a learning management system (LMS), or other software products, to provide instruction and disseminate information and knowledge that assists students with the transition to university (Cidral et al., 2018; Mayer, 2017). Typically, online orientation programs are delivered as asynchronous, self-paced, modular courses. While 2020 saw explosive growth in online orientation programs, they are not entirely new. According to a 2013 NODA survey, 26\% of institutions offered an online orientation program, with $18 \%$ of institutions offering an online orientation for first-year students. Others offered programs for transfer students, international students, graduate students, or other student populations (NODA, 2013). For many institutions, online orientation programs began as a way to offer transition support for online learners. For other institutions, the online format initially served student groups who could not come to campus before the beginning of the term, such as international students and out-ofprovince or out-of-state students. Still, other institutions have offered an online program as an additional orientation component, increasing the transition support available for new students. 
As with in-person orientation programming, the content of an online orientation differs between institutions depending on their goals. Some programs will focus on academic information, course registration, and introducing students to campus resources. In contrast, others may aim to teach students academic or personal (e.g., developing a budget) skills, prevent sexual violence, encourage good choices about substance use, and help students manage their mental health, among other student life and development topics. Similarly, institutions may differ in how they deliver content, with options including text, images, video, quizzes, interactive activities, discussion boards, and more.

\section{Benefits and Challenges of Going Online}

While most institutions turned to online orientation for health and safety reasons in 2020, there are many benefits to having an online orientation program. An online orientation program offers convenience for students and can increase access (Etherington et al., 2017; Means et al., 2013). Removing the requirement to be in a designated place at a designated time reduces geographic, scheduling, and financial barriers to participation. Taking orientation online also allows the program to function as not just an event but as an ongoing resource, enabling students to revisit content whenever they need it (Gayed et al., 2018; Korstange et al., 2020).

An online orientation program may also offer the opportunity to create a more learner-centered experience than a traditional in-person program can. Students can choose when they want to engage in the learning opportunity, work at their own pace, and skip sections of the program they feel will not be helpful (Baker \& Etherington, 2016; Etherington et al., 2017; Strother, 2002). Online orientation programs can also provide an opportunity to include a variety of different learning activities, allowing students to interact with the content and receive immediate feedback on their learning-something that is not always possible in a large-scale orientation program (Ard \& Ard, 2019; Jacklin \& Robinson, 2013; Means et al., 2013).

Offering an online orientation program can also be beneficial for the institution. While there may be a significant initial investment required to get a program up and running, online orientation can be less expensive over time than a comparable in-person program (Baker \& Etherington, 2016; Means et al., 2013). The staff time and resources needed to update and run an online orientation program every year are generally less than what is needed to plan and run in-person programming. Recurring costs associated with hiring session facilitators and orientation leaders, booking space on campus, and hiring a caterer may be eliminated (Baker \& Etherington, 2016; Jacklin \& Robinson, 2013). An online orientation program can be used many different times, for different student intakes, with minimal changes. Much of the work involved in running online orientation sessions happens before program launch, leaving orientation staff available to respond to student needs and requests instead of focusing on program logistics (Gayed et al., 2018). Finally, online orientation programs can tailor content to different student populations (Korstange et al., 2020). Overall, online orientation can be a more flexible, time-effective, and economical means of providing programming to a large number of students than an in-person event (Gayed et al., 2018).

Implementing an online orientation program is not without its challenges and drawbacks, however. Designing an online program often requires a different skill set than planning an in-person event. Instead of scheduling and logistics, the student affairs professional must be familiar with technology, instructional design, and online learning. Even with support from IT professionals, a learning designer, or an outside software company, OTR professionals will likely need some knowledge of the software platform; of the technology and processes involved in creating audio, graphics, video, screencasting, and more; and of digital accessibility (Jacklin \& Robinson, 2013). Online orientation programs also generally offer fewer opportunities for peer connection than in-person programs. They rarely help students connect with other students or university staff who can 
offer assistance and answer questions (Jacklin \& Robinson, 2013). While the flexibility these programs provide is beneficial, they also require students to demonstrate a higher level of commitment, motivation, and planning than in-person programs (Taylor, 2015).

\section{Effectiveness of an Online Orientation Program}

While research on online orientation programs is limited, the effectiveness of online learning, in general, has been studied across a range of fields and content areas, from health to business to library sciences and more. Across all content areas, researchers have found online learning to be an effective format for knowledge acquisition and attitude improvement (Baker \& Etherington, 2016). At a minimum, it is equally effective as traditional, face-to-face learning (Etherington et al., 2017; Means et al., 2013; Ramage, 2002).

Research in several different areas of online learning provides support for the potential effectiveness of online orientation programs. Online modules and programs that focused explicitly on topics similar to those covered in traditional orientation programs, such as academic skills (Brown et al., 2008; Moore et al., 2014), academic integrity (Benson et al., 2019), mental health (Gayed et al., 2018), substance use (Beeson et al., 2019), sexual violence (Etherington et al., 2017), and information literacy (Ard \& Ard, 2019; Jacklin \& Robinson, 2013; Marineo \& Shi, 2019), have been found to be effective at achieving the desired learning outcomes and result in student satisfaction. Online orientation programs for online learners, which often focus on program requirements, the technology required for online learning, and available supports and services, have been found to increase a student's sense of readiness (Jones, 2013; Liu, 2019) and decrease the number of technical problems (Jones, 2013). In some cases, students who completed the program earned higher GPAs and were more likely to be retained than students who did not complete the program (Jones, 2013; Taylor, 2015). Additionally, in student surveys, participants indicated the programs were helpful and that they were satisfied with their experience (Taylor, 2015).

While more research on online orientation programs for face-to-face students is needed, two different studies independently demonstrate the impact and effectiveness of these programs. Participants in an online orientation program at Western University in London, Ontario, achieved higher scores on the Student Adaptation to College Questionnaire (SACQ) and higher end-of-term grades than non-participants (Hanna-Benson, 2019). Similarly, an online orientation program offered at a mid-sized community college in the mid-Atlantic region of the United States resulted in a higher fall-to-spring retention rate and first semester GPA for students who completed the program as compared to those who did not (Colucci \& Grebing, 2020).

\section{The Community of Inquiry Model}

Advice about online learning is widely available; however, such advice will only be minimally helpful when used in isolation. Placing that advice within a more comprehensive online learning framework can increase its utility. The community of inquiry model is a popular conceptual framework that identifies three primary factors in a quality online learning experience: (a) teaching presence, (b) social presence, and (c) cognitive presence (Garrison et al., 1999). While this model is most commonly used in the design of higher education courses, it has also been used in online training environments (Singleton, 2019) and for online orientation programs (Watts, 2019). These factors are defined below. Practices designed to enhance presence in each of these areas are explored in the remainder of this literature review.

Teaching Presence (or Setting Up Your Course)

Teaching presence is defined as "the design, facilitation and direction of cognitive and social processes for 
the purpose of realizing...learning outcomes" (Joo et al., 2011, p. 1655). For an online, asynchronous, self-paced course, teaching presence is created through the design and management of the course. It includes components such as the design and organization of the course platform, creation of learning activities, and communication with learners. In an online orientation program, teaching presence is essentially the invisible hand guiding students through the course. Usability, user-interface design, help and support, and visual design are related to the learner's ability to navigate a course successfully and remain focused on the content. Teaching presence also relates to the design of learning activities, but as this also touches on cognitive presence, that discussion is elsewhere in this literature review.

Choosing a platform. The online learning platform impacts usability, access, assessment, the types of activities available, cost, and more. Generally, online orientation programs are hosted on one of three platform types: a website, the institution's LMS, or a software product (Chan, 2017). Each option has benefits and drawbacks. A website offers the ability to share text, images, and video in a structured format but has limited interactivity with polls and quizzes. If login is not required, the website does not offer the ability to track individual users' behavior. Using the institution's LMS means that the course is hosted in the same system students will access for their academic courses, allowing them to become familiar with the system ahead of time. The LMS allows for the use of text, images, videos, polls, quizzes, and surveys, among other features, and can often track user behavior in many ways, including measuring the number of logins, completion of activities, and time spent per activity. However, an LMS may have a rigid structure and is more restrictive when it comes to access, frequently requiring an institutional login. Software products are often used for online orientation when an institution has chosen to work with an external vendor specializing in this area. These products are typically well-designed and visually appealing, allow for text, images, video, polls, quizzes, and surveys and connect with institutional systems for the purpose of data tracking. For some institutions, these products can be costprohibitive. The initial set-up fee and the yearly subscription can cost tens of thousands of dollars per year. These products can also be rigid and inflexible in structure, often delivering content quite linearly. They may also be restrictive when it comes to access, requiring a login.

Usability. The online course needs to have a high degree of usability to support participation in the program. Usability is a measure of how easily learners can complete the essential tasks associated with the course, such as enrolling in the course platform, navigating through the course, uploading assignments, posting in forums, watching video clips, or submitting quiz answers (Gamage et al., 2015; Heidig et al., 2015; Long et al., 2009). Learners who can complete these tasks with ease are more likely to be satisfied with the course, while those who struggle are less likely to be motivated to engage with course content and less likely to finish the course (Cho et al., 2009; Long et al., 2009). While usability is essential for every online course, it may matter more in short, intensive courses, such as an online orientation, as learners are unwilling to invest much time learning a system they will only use briefly (Mulvaney, 2020).

A significant component of the usability of a course is dictated by the user interface design (what a user sees and interacts with as they navigate through the course) and the organization of course content (Cho et al., 2009). A well-designed course minimizes the effort a learner needs to expend when using a system by providing a clear picture of what is required to complete the course and making course navigation easy. The course layout should ensure all content, activities, and features are easy to access and not hidden in hard-to-find places.

Navigating from one piece of content to the next should be a straightforward and easy process (Chan, 2017; Cho et al., 2009; Heidig et al., 2015). Information should be organized logically, with related content grouped (Cho et al., 2009). These groupings should be made explicit through headings, page breaks, and visual separators (e.g., lines or boxes). Learners should have an overview of all modules and topics being covered and fully grasp the 
course structure. Sub-topics should also be evident to the learner from the homepage (Eaton et al., 2018; Janicki \& Liegle, 2001). Finally, the system should prominently display information about a learner's progress in the course, making it easy to identify which activities have been completed and how much work is left to do (Cho et al., 2009).

Usability is about navigating the online learning system and understanding how to complete the activities within the program. Providing clear instructions is critical (Jacklin \& Robinson, 2013). Learners need to understand what they are being asked to do within an activity from a learning and application perspective and how to accomplish that within the learning system. In an online environment, the learner has fewer context clues available, cannot easily observe how their peers are completing the activity, and does not have immediate access to an instructor to ask for clarification (Jacklin \& Robinson, 2013). Additionally, learners are often less comfortable asking questions in an online environment, as they may have no relationship with or knowledge of the person to whom they are sending the question (Janicki \& Liegle, 2001). As such, instructions may need to be more explicit than they would be for an equivalent in-person activity.

Mitigating technology problems. With any online process, technology problems are always a possibility, and it is important to take steps to mitigate possible problems before launching a course. If a learner regularly encounters technology problems, their ability to learn course content and meet course objectives is at risk (Karthik et al., 2019). They may skip content or entire sections of the course or give up on completing the course altogether (Long et al., 2009). For learners who were not feeling particularly motivated to begin with, technology problems significantly increase the likelihood they will abandon a course (Cidral et al., 2018).

Instructors can take several steps to mitigate technology problems in their courses. When choosing technology tools, instructors should ensure they work on a variety of devices and are not prone to system crashes (Heidig et al., 2015). They should also be careful not to overload course pages with too many media files, such as images, videos, and audio clips, as this content tends to extend the loading time of pages. If a page takes too long to load, a learner may lose interest or believe there is an error, leaving the page rather than waiting (Heidig et al., 2015). A learner's tolerance for waiting decreases the longer they interact with the system (Heidig et al., 2015). A course should also be rigorously tested before going live.

It is unlikely that an instructor can eliminate every technology problem, so technical assistance must be readily available (Karthik et al., 2019). Strategies for providing technical support include identifying possible issues and providing solutions in an FAQ page, creating a discussion board where learners can post technology questions and get solutions from the instructor or fellow learners, or encouraging learners to take a virtual tour of the course environment before the course begins and proactively solve any problems they encounter (Karthik et al., 2019).

Visual design. Most instructors are not user-experience designers, nor do they typically have extensive graphic design experience. However, it is important to be aware that the look and feel of the course and activities matter (Karthik et al., 2019). Pages should be visually appealing, and thought should be given to colors, shapes, fonts, and white space. A visually stimulating design increases the time the learner spends on the page. It also leads learners to believe that the course is easily navigable and that usability will be high, which positively affects a learner's intentions to engage in the course and their usage behavior (Karthik et al., 2019; Lim et al., 2007).

\section{Cognitive Presence (or Content Creation)}

The second factor in the community of inquiry model is cognitive presence, the "exploration, construction, resolution and confirmation of understanding" (Joo et al., 2011, p. 1655). Essentially, cognitive presence is the intellectual and mental effort and processes required for learning. In an online orientation program, cognitive presence is primarily created through the design and delivery of content and learning activities. 
Creating content and learning activities. In an online learning environment, there are many different ways to structure and deliver content. Instructors can choose to use strategies such as storytelling, problembased learning, inquiry-based learning, direct instruction, or gamification, and learning activities can be delivered via a variety of different media, such as text, images, video, podcasts, or interactive activities (Arghode et al., 2018; Karthik et al., 2019). These interactive activities can be built using features of an LMS or software such as Kaltura, H5P, or Articulate 360. Table 1 outlines the structure and chosen approach to learning activities for several different online training and orientation programs.

Table 1.

Structure and Chosen Approach to Learning Activities for Several Different Online Training and Online Orientation Programs

\begin{tabular}{|c|c|c|c|}
\hline Topic & Structure & Learning activities & Source \\
\hline Library instruction & $\begin{array}{l}2 \text { modules, } 20 \text { minutes } \\
\text { each; final test }\end{array}$ & $\begin{array}{l}\text { Narrated slides (using } \\
\text { Adobe Captivate), written } \\
\text { responses, interactive } \\
\text { drag-and-drop games, and } \\
\text { real-life scenarios }\end{array}$ & Ard \& Ard (2019) \\
\hline Substance use & $\begin{array}{l}10 \text { self-paced modules; } \\
4-6 \text { hours total }\end{array}$ & $\begin{array}{l}\text { Brief video lectures, } \\
\text { personal stories, } \\
\text { reflection prompts, } \\
\text { module quizzes }\end{array}$ & Beeson et al. (2019) \\
\hline Academic integrity & $\begin{array}{l}4 \text { modules; summative } \\
\text { quiz }\end{array}$ & $\begin{array}{l}\text { Designed using the } \\
\text { Articulate } 360 \text { software } \\
\text { suite and offers several } \\
\text { embedding features and } \\
\text { pre-built interactions } \\
\text { such as card sorting, } \\
\text { flashcards, knowledge } \\
\text { checks, click-through } \\
\text { processes, and pre-built } \\
\text { timeline features }\end{array}$ & Benson et al. (2019) \\
\hline Academic writing & 6 modules & $\begin{array}{l}\text { Audio-visual } \\
\text { presentations }\end{array}$ & Brown et al. (2008) \\
\hline Sexualized violence & 4 units; 8 topics total & No information & Etherington et al. (2017) \\
\hline Mental health & $\begin{array}{l}3 \text { topics; } 15 \text { 10-minute } \\
\text { modules total }\end{array}$ & $\begin{array}{l}\text { Text, short videos, } \\
\text { practical activities, topic } \\
\text { summary exercises }\end{array}$ & Gayed et al. (2018) \\
\hline $\begin{array}{l}\text { Online orientation for } \\
\text { online learners }\end{array}$ & $\begin{array}{l}10 \text { modules; cumulative } \\
\text { final }\end{array}$ & $\begin{array}{l}\text { Each module has an } \\
\text { interactive activity. }\end{array}$ & Jones (2013) \\
\hline
\end{tabular}




\begin{tabular}{|c|c|c|c|}
\hline $\begin{array}{l}\text { Online orientation for } \\
\text { online learners }\end{array}$ & 5 modules & $\begin{array}{l}\text { Text, images, videos, } \\
\text { embedded self-directed } \\
\text { learning activities, } \\
\text { discussion posts, } \\
\text { assignment submission, } \\
\text { quiz }\end{array}$ & Liu (2019) \\
\hline $\begin{array}{l}\text { Online orientation for } \\
\text { online learners }\end{array}$ & No information & $\begin{array}{l}\text { Short video tutorials } \\
\text { (<4 min) that included } \\
\text { interactive self- } \\
\text { assessments; built using } \\
\text { Articulate Storyline and } \\
\text { Camtasia Studio }\end{array}$ & Taylor (2015) \\
\hline $\begin{array}{l}\text { Online orientation for } \\
\text { online learners }\end{array}$ & $\begin{array}{l}3 \text { modules; pre- and post- } \\
\text { assessment }\end{array}$ & $\begin{array}{l}\text { 10-minute video + } \\
\text { accompanying blog post, } \\
\text { discussion board, two- } \\
\text { page response paper to a } \\
\text { study }\end{array}$ & Watts (2019) \\
\hline Online orientation & 6 modules & $\begin{array}{l}\text { Graphics, videos, and } \\
\text { interactive activities in } \\
\text { Articulate Storyline }\end{array}$ & Hanna-Benson (2019) \\
\hline
\end{tabular}

When considering the type of media to use for learning activities, it is important to remember that the medium itself does not influence learning; the choice should be based on the pedagogical approach desired and the resources and expertise available to design and implement the activity (Clark, 1994; Clark \& Feldon, 2014). Where possible, activities should promote active learning and interaction. Instructors should ensure they are not carried away by features of the online delivery platform; instead, they should remain focused on the pedagogical aspects of content delivery (Ard \& Ard, 2019; Drago et al., 2002; Rodrigues et al., 2019). Depending on the medium chosen, instructors should attend to additional design considerations when creating the learning activity. These include the following:

- Text. Text often forms part of an online course, either as a stand-alone activity type or as part of other media. While text can be an effective means to convey information and promote learning, many learners prefer multimedia courses and activities and will express dissatisfaction with text-heavy resources (Clark \& Feldon, 2014). This dissatisfaction likely has more to do with which medium they think provides the easier path to achievement as opposed to which results in greater learning. Text in online courses should be written in an informal, conversational tone, speaking directly to the learner. This allows the learner to feel connected to what is being said and to more easily incorporate the knowledge into their existing schema. (Ard \& Ard, 2019; Benson et al., 2019; Clark \& Feldon, 2014). Text should be written in short sentences and paragraphs and make use of headings so as to help the learner follow the narrative and not get lost on the page.

- Video. When creating instructional videos, it is important to ensure the video is engaging so that it will be viewed in its entirety. To ensure that the learner can focus on the content, videos should have highquality audio, images should be clear and well-lit, and busy screens should be avoided (Weeks \& Davis, 2017). Videos should be focused on a single topic and kept to 2 - 3 minutes in length. Shorter 
videos are more likely to be viewed to the end and reduce the cognitive load for a learner, allowing them to more fully digest one subject before being introduced to another (Weeks \& Davis, 2017). The beginning of a video should clearly state the learning objective so that a learner knows what to expect. This introduction should be kept short and to the point so as not to lose a viewer before the video even begins addressing the content (Weeks \& Davis, 2017). Finally, the presenter can create a social connection with the learner by speaking with enthusiasm, avoiding sounding like they are reading from a script, and allowing their image to appear on screen (Mayer, 2017).

- Multimedia. Learning activities in an online course are often delivered via some form of multimedia, which consists of a combination of words and pictures. The words may be either spoken or narrated, and the pictures may be static, such as illustrations, diagrams, and photos, or dynamic, such as animations or video. When creating multimedia for learning, design decisions should prioritize helping learners select, organize, and integrate knowledge without overloading the visual and verbal channels in working memory (Mayer, 2017). Several principles have been identified to help in each of these areas.

- In any multimedia learning activity, extraneous processing, or any cognitive processing that is not directly related to the learning objective, should be reduced, if not eliminated. While instructors may be tempted to include fun, interesting details, students learn better when extraneous material is excluded. Otherwise, that material takes up space in their working memory (Mayer, 2017). Students also learn better when essential material is emphasized in some way, whether it is via headings, bold font, or highlighted text. Visual cues draw a learner's attention to what is most important and make the organization of material clear (Mayer, 2017). When using graphics or diagrams, explanatory words should be placed next to the corresponding part of the graphic, and narration should be presented simultaneously instead of sequentially in order to make the connection between the content explicit (Mayer, 2017).

- Essential processing refers to the cognitive processing required to mentally represent the required material and is determined by the complexity of the learning material. Any steps that can be taken to reduce complexity will increase learning (Mayer, 2017). Segmenting content, incorporating pre-training, and narrating graphics are all ways to reduce this complexity (Mayer, 2017). Segmenting involves breaking the lesson into small, user-paced chunks; the smaller, the better. This allows a learner to digest one chunk of information before moving on (Mayer, 2017). Pre-training involves teaching the learner the key terminology used in the lesson prior to receiving the lesson. The learner will then be able to focus on the content, building connections between concepts instead of on what various terms mean (Mayer, 2017).

Providing feedback. Feedback is a crucial element in online learning environments and is essential for self-motivation (Marks et al., 2005; Mulvaney, 2020). Feedback can sometimes be built into activities within the online learning system. At other times, feedback is provided after the instructor has reviewed the activity. In all cases, learners should be provided with a timeframe in which they should expect to receive feedback, and this feedback should be provided as quickly as possible (Arghode et al., 2018; Joo et al., 2011). Using embedded questions within a learning activity or having a short quiz at the end of a module can be an efficient and effective means of checking learner understanding and providing feedback (Chan, 2017; Clark \& Feldon, 2014).

Ideal feedback will be more than just "correct/incorrect." Learners should be informed as to why their answer is wrong, provided with an explanation of any errors they have made, and in some cases, reminded of the goal of the exercise (Clark \& Feldon, 2014; Janicki \& Liegle, 2001). If a learner seems to be struggling to figure out the correct answer, they should be given hints. Feedback should be justifiably critical but also contain elements 
of support and positive reinforcement (Marks et al., 2005; Paechter et al., 2010). Finally, feedback should be provided in complete sentences and presented in the same location and in the same format for every question (Janicki \& Liegle, 2001).

\section{Social Presence (or Community Building)}

Social presence, the final factor in the community of inquiry model, refers to "the ability of participants to project their personal characteristics into the community, thereby presenting themselves to the other participants as 'real people'" (Garrison et al., 1999, p. 32). Social presence allows learners to feel comfortable sharing their thoughts, feelings, and experiences with their peers and shifts online learning away from being a simple process of downloading information toward an experience that creates a real feeling of community (Garrison et al., 1999; Joo et al., 2011). In the context of an online orientation program, social presence may relate to creating peer-to-peer connections, allowing space for vulnerability within the course, and connecting learners to the larger university community.

Creating peer-to-peer social connections. Social connection and peer-to-peer learning have both been found to be important aspects of a quality online learning experience. Social connection can enhance a learner's satisfaction with the course, their perception of learning outcomes, their level of interaction, and their motivation (Montgomerie et al., 2016). Social connection and peer-to-peer learning can be built into an online course in many ways, including peer review, discussion boards, and collaborative projects (Hall, 2015; Jaggars \& Xu, 2016; Karthik et al., 2019). Many of these methods lend themselves more readily to 12-week academic courses than to self-paced, asynchronous modules. Peer review is difficult to set up in a self-paced course, as students do not be complete activities at the same time. Also, since the course is not graded, students would have little incentive to invest time and energy in the peer review process. Further, all learners in an online orientation program are equally unfamiliar with the university experience; thus, it is unlikely they would be able to offer their peers much advice or insight. Collaborative projects in an online orientation program have many of the same drawbacks as peer review: They are difficult to set up due to the self-paced nature of the experience and require too much time and energy.

Discussion boards are a common activity type used in self-paced, asynchronous courses and can be beneficial when asking students to reflect on what they have learned. However, in self-paced courses, discussion boards rarely work to connect learners with each other or create social presence (Liu, 2019). While students have the option to read and respond to the posts of other learners, they rarely return to a previous activity to see what has been posted since they completed it.

Incorporating student voice. With online orientation programs, the goal may need to shift from creating a community within the course toward welcoming students to a community within the institution. Orientation leaders are one of the most influential aspects of many in-person orientation programs, as they share their own personal student experiences, provide advice, and answer questions that new students may not feel comfortable asking a university staff member (Ganser \& Kennedy, 2012; Richardson \& Tate, 2013). Upper-level students can play a similar role in an online orientation program by sharing their personal experiences through video, student profiles, quote bubbles, or other methods (Ganser \& Kennedy, 2012).

Incorporating the voices of current students into an online orientation program can have many benefits. Reflecting on these benefits can help an instructor determine which stories to share and where in the program to share them. First, upper-level students often act as role models for new students and convey the values, norms, and expectations of the institution, along with the types of behavior that are socially acceptable (Ganser \& Kennedy, 2012; Peregrina-Kretz et al., 2018; Richardson \& Tate, 2013). Second, upper-level students can be a source of empathy, validation, and reassurance for new students. The stories of upper-level students can help 
new students know that others have experienced similar challenges, offer strategies for navigating the challenge, and demonstrate that the challenge is surmountable (Peregrina-Kretz et al., 2018; Richardson \& Tate, 2013). Finally, the stories upper-level students tell can reinforce the knowledge shared elsewhere in the program and help connect new students to programs and services on campus. Because the information is coming from a peer, students are more likely to value it and act upon it (Ganser \& Kennedy, 2012; Peregrina-Kretz et al., 2018; Richardson \& Tate, 2013).

Ongoing role of the instructor. While incorporating student voice can be one way to build community and social presence within an online orientation program, considering the role of the instructor can be another way to make students feel they are a part of a supportive community. In many online, asynchronous, self-paced courses, the instructor is simply the invisible hand behind the creation of the course. However, an instructor can make themselves more visible in a number of ways. The first is through the promotion of, and communications related to, the program. Communications written in first-person, directly to the individual student, and signed with the name of a real person, rather than an office or department, can make a student feel more connected to the instructor (Benson et al., 2019). The use of an anchoring figure, a recurring person or narrator who provides continuity throughout the course, can also increase instructor presence and create a sense of familiarity and comfort for a student (Benson et al., 2019). This anchoring figure may appear in videos, through quotes with a picture, or in other creative ways. By providing continuity, the anchoring figure not only increases social presence but also comprehension and retention of information (Benson et al., 2019).

\section{Attrition and Completion}

Putting together an engaging and effective online orientation program is only one piece of the puzzle. Once the program has been created, the process to get students to complete it begins. Some institutions may be able to make online orientation mandatory, requiring students to complete the program before they can register for courses or receive their student ID. For many institutions, however, completion of the program will likely be strongly recommended but entirely voluntary.

Attrition rates for online learning courses, in general, are quite high. In for-credit university and college courses, attrition is often 15 - 20 percentage points higher than in face-to-face courses. MOOCs have an attrition rate around $97 \%$. These high attrition rates are also seen in many self-paced online training programs, as well as many online orientation programs (Levy, 2007; Reich \& Ruipérez-Valiente, 2019). In many cases, the invited participants never enroll in the program at all. In a study of a self-paced academic integrity course offered at a large university in northwest England, only a third of the students who were given access to the course ever accessed the available resources (Brown et al., 2008). Of the students who did visit the course, the majority did not access all the content available. In an online orientation program offered at a community college in the United States, $39.1 \%$ of students completed the program, while a further $24.1 \%$ accessed some of the program's content (Colucci \& Grebing, 2020). Finally, in the first year of an online orientation program for health science students at Western University, only $44 \%$ of students visited the program. Of those, only $17 \%$ completed the program (Hanna-Benson, 2019), which represented $8 \%$ of the invited population. In subsequent years, changes to the program resulted in $42 \%$ of visiting users (i.e., $34 \%$ of the invited population) completing the entire program. Since the premise of orientation programming is that it is beneficial to all incoming first-year students, these numbers indicate that there is still work to be done to capture the remaining two thirds of students.

\section{Reasons for Attrition in Online Courses}

Learners do not complete online courses for many reasons though most fall into two categories: poor course design and contextual factors surrounding the learner (Long et al., 2009). Course design factors include 
enrollment processes, ease of technology use, and course navigation (Long et al., 2009). If learners struggle with accessing the course, getting set up, or figuring out how to start and where to go next, they are less likely to finish the course. Additionally, if they regularly encounter technology problems while navigating the course, they have an increased likelihood of giving up. These factors are amplified in learners who were not feeling particularly motivated, to begin with, or who experience computer anxiety (Cidral et al., 2018). Course design factors also include the appropriateness, clarity, and presentation of the content, as well as of assignments and assessment techniques (Long et al., 2009). Learners who believe that a course is interesting, useful, and important are more likely to be satisfied with the course while enrolled, leading to a higher rate of persistence and completion (Artino, 2008).

Contextual factors that impact online course completion may relate to social support, situational constraints, or personal constraints. In a workplace setting, learners with managers who show an interest in the training are more likely to complete it (Long et al., 2009). Managers who show an interest demonstrate that they perceive the training as useful and thereby influence the learner's perception of the usefulness of the training as well. Interest from parents, family, and peers or a positive recommendation about the program from a current student or another first-year student can have a similar positive effect on course completion.

Situational constraints can have a large impact on course completion, with the most common reason given for not completing a course being insufficient time (Brown et al., 2008; Long et al., 2009). Learners may find they do not have enough time because they are busy throughout the entire duration of the program or because they leave it until the last minute (Brown et al., 2008). Learners may also make their own judgments about the usefulness of the content in a course. They may feel as though they already know the content, so they do not need to complete the course at all, or they pick and choose the content they believe is useful to them and drop out of the course once they feel they have learned what they needed to know (Brown et al., 2008; 0'Connor et al., 2003).

Personal constraints, such as computer anxiety, familiarity with technology, and personal motivation all influence course completion (Long et al., 2009). As mentioned previously, learners with computer anxiety or who struggle with technology have an increased likelihood of not completing if they encounter technological difficulties (Cidral et al., 2018). As personal motivation has been found to be the most reported factor leading to course completion, it stands to reason that a lack of motivation would subsequently lead to attrition (O'Connor et al., 2003).

\section{Promoting and Incentivizing the Course}

As a first step to getting learners to complete an online orientation program, it is important to ensure that the learner knows that the program exists and can identify one or more reasons why they should complete the program. Such reasons should spur them to enroll or access the program initially. Regular promotion of the program is crucial, and any promotional content should clearly convey the purpose and benefits of participation (Eaton et al., 2018; Gayed et al., 2018). Program marketing should be strategically planned and include repeated outreach to students, using varied outreach strategies (i.e., email, social media, call campaign, in-person promotion, etc.), and modification of the messages contained within each outreach attempt (Eaton et al., 2018; Gayed et al., 2018). At Griffith University, where each faculty (i.e., college or school) had a separate orientation website for their students, the faculties who strategically planned repeated outreach to students to promote the site saw higher numbers of students accessing and engaging with the program than faculties whose outreach was limited (Eaton et al., 2018).

Incentivizing participation and completion can also be an effective strategy to increase engagement (HannaBenson, 2019). This often looks like providing a giveaway that a learner will receive upon completing a section 
of the program or the program in its entirety or offering a learner the chance to win a prize based on program completion. These incentives attract a learner's attention initially, drawing them into the program and creating a source of extrinsic motivation.

There are a few factors to consider when implementing an incentive. First, the incentive must align with the amount of work required (Keller, 2008). Offering students a chance to win a $\$ 10$ gift card in exchange for spending four hours completing a program, for example, will likely not be effective as an incentive for most students. While there are no set standards governing incentive amounts, it is important that students do not feel belittled by the incentive being offered. Incentives of higher value are often more successful than similar incentives of lower value (i.e., a $\$ 500$ gift card as opposed to a $\$ 100$ gift card). The second consideration requires a reflection on what the learner may value most as an incentive. A 2019 study of Western University's LegUp online orientation program found that switching the incentive from a chance to win a $\$ 250$ gift card to an automatic $2 \%$ grade increase in a specific first-year course increased the percentage of invited participants who completed the program from $8 \%$ to 34\% (Hanna-Benson, 2019). A direct grade increase works as an incentive for some learners-especially those who may be extrinsically motivated. Promising learners better grades due to knowledge and skills gained by completing the program may not have the same impact for students in this category (Brown et al., 2008). The final consideration when implementing an incentive is to ensure that it does not have a detrimental effect on intrinsic motivation. Similarly, it is important to ensure that messaging about the benefits of the program does not get lost amid the promotion of incentives (Artino, 2008).

While promoting and incentivizing the course are both helpful in getting students to access online programs, personalized email reminders have an important role to play in getting learners across the finish line to completion (Gayed et al., 2018). Designing these emails based on Keller's ARCS theory of motivation can improve their effectiveness at eliciting the desired behavior (Kim \& Keller, 2008). This means considering the reasons why a learner may not have completed the program, analyzing their motivational requirements, and then designing strategies pertaining specifically to the identified needs and requirements. In particular, this may mean addressing the email to the individual student and capturing their attention and curiosity, which leads them to believe that the message is specifically for them (attention). Effective messages will also include information related directly to the learner, such as the specific parts of the program they have not yet completed or referring to responses given in the program (relevance). Encouraging learners to believe that they can achieve the goal of finishing the course (i.e., by breaking down the time requirement into chunks that seem reasonable to a busy learner) or a different goal, with the help of the program in question, is also an effective strategy (Kim \& Keller, 2008).

\section{Conclusion}

As orientation continues to change and evolve in order to meet student needs and support an institution's mission and retention goals, online programs are becoming increasingly common. Using the community of inquiry model and considering cognitive presence, teaching presence, and social presence when designing or updating an online orientation program can help a student affairs professional think through the best type of learning activities, the structure and design of the course system, and strategies for supporting a student throughout the course and incorporating student voices. Understanding how online programs might be used to incorporate students into the existing campus community is another crucial step. Combining the community of inquiry model with the more practical online learning practices outlined in this literature review can help ensure an online orientation program creates an effective and engaging experience for students. 


\section{References}

Ard, S. E., \& Ard, F. (2019). The library and the writing centre build a workshop: Exploring the impact of an asynchronous online academic integrity course. New Review of Academic Librarianship, 25(2-4), 218-243. https://doi.org/10.1080/13614533.2019.1644356

Arghode, V., Brieger, E., \& Wang, J. (2018). Engaging instructional design and instructor role in online learning environment. European Journal of Training and Development, 42(7/8), 366-380. https://doi.org/10.1108/ EJTD-12-2017-0110

Artino, A. R. (2008). Motivational beliefs and perceptions of instructional quality: Predicting satisfaction with online training. Journal of Computer Assisted Learning, 24(3), 260-270. https://doi.org/10.1111/j.13652729.2007.00258.x

Baker, L., \& Etherington, N. (2016). Gender-based violence training programs: Online, face-to-face and blended formats. Centre for Research \& Education on Violence Against Women \& Children.

Beeson, E. T., Ryding, R., Peterson, H. M., Ansell, K. L., Aideyan, B., \& Whitney, J. M. (2019). RecoveryZone: A pilot study evaluating the outcomes of an online ally training program. Journal of Student Affairs Research and Practice, 56(3), 284-297. https://doi.org/10.1080/19496591.2018.1474765

Benson, L., Rodier, K., Enström, R., \& Bocatto, E. (2019). Developing a university-wide academic integrity e-learning tutorial: A Canadian case. International Journal for Educational Integrity, 15(1), 5. https://doi. org/10.1007/s40979-019-0045-1

Brown, C. A., Dickson, R., Humphreys, A.-L., McQuillan, V., \& Smears, E. (2008). Promoting academic writing/ referencing skills: Outcome of an undergraduate e-learning pilot project. British Journal of Educational Technology, 39(1), 140-156. https://doi.org/10.1111/j.1467-8535.2007.00735.x

Chan, M. (2017). Have you been oriented? An analysis of new student orientation and e-orientation programs. College and University, 92(2), 12-25.

Cho, V., Cheng, T. C. E., \& Lai, W. M. J. (2009). The role of perceived user-interface design in continued usage intention of self-paced e-learning tools. Computers \& Education, 53(2), 216-227. https://doi.org/10.1016/j. compedu.2009.01.014

Cidral, W. A., Oliveira, T., Di Felice, M., \& Aparicio, M. (2018). E-learning success determinants: Brazilian empirical study. Computers \& Education, 122, 273-290. https://doi.org/10.1016/j.compedu.2017.12.001

Clark, R. E. (1994). Media will never influence learning. Educational Technology Research and Development, 42(2), 21-29. https://doi.org/10.1007/BF02299088

Clark, R. E., \& Feldon, D. F. (2014). Ten common but questionable principles of multimedia learning. In R. Mayer (Ed.), The Cambridge Handbook of Multimedia Learning (2nd ed., pp. 151-173). Cambridge University Press. https://doi.org/10.1017/CB09781139547369.009

Colucci, R. L., \& Grebing, R. E. (2020). The impact of an online orientation program on student success at a community college. Journal of College Orientation, Transition, and Retention, 27(1), Article 1. https://doi. org/10.24926/jcotr.v27i1.2251

Drago, W., Peltier, J., \& Sorensen, D. (2002). Course content or the instructor: Which is more important in online teaching? Management Research News, 25(6/7), 69-83. https://doi.org/10.1108/01409170210783322

Eaton, R., Sharples, J., \& Buys, N. (2018). Toolkit for success: The Griffith Health suite of online student support resources. Student Success, 9(3), 65-70. https://doi.org/10.5204/ssj.v9i3.469

Etherington, N., Baker, L., Ham, M., \& Glasbeek, D. (2017). Evaluating the effectiveness of online training for a comprehensive violence against women program: A pilot study. Journal of Interpersonal Violence. Advanced online publication. https://doi.org/10.1177/0886260517725734 
Gamage, D., Fernando, S., \& Perera, I. (2015). Effectiveness of eLearning: Grounded theory approach. Moratuwa Engineering Research Conference, 336-341. https://doi.org/10.1109/MERCon.2015.7112369

Ganser, S. R., \& Kennedy, T. L. (2012). Where it all began: Peer education and leadership in student services. New Directions for Higher Education, 2012(157), 17-29. https://doi.org/10.1002/he.20003

Garrison, D. R., Anderson, T., \& Archer, W. (1999). Critical inquiry in a text-based environment: Computer conferencing in higher education. The Internet and Higher Education, 2(2), 87-105. https://doi. org/10.1016/S1096-7516(00)00016-6

Gayed, A., LaMontagne, A. D., Milner, A., Deady, M., Calvo, R. A., Christensen, H., Mykletun, A., Glozier, N., \& Harvey, S. B. (2018). A new online mental health training program for workplace managers: Pre-post pilot study assessing feasibility, usability, and possible effectiveness. JMIR Mental Health, 5(3), e10517. https://doi. org/10.2196/10517

Hall, R. A. (2015). Critical thinking in online discussion boards: Transforming an anomaly. Delta Kappa Gamma Bulletin, 81(3), 21-27.

Hanna-Benson, C. (2019). Development and evaluation of an online university readiness course furthered by capturing the lived experience of students during this transition: A multi-perspective understanding of the transition to university [Doctoral dissertation, Western University]. https://ir.lib.uwo.ca/etd/6092

Heidig, S., Müller, J., \& Reichelt, M. (2015). Emotional design in multimedia learning: Differentiation on relevant design features and their effects on emotions and learning. Computers in Human Behavior, 44. https://doi. org/10.1016/j.chb.2014.11.009

Jacklin, M., \& Robinson, K. (2013). Evolution of various library instruction strategies: Using student feedback to create and enhance online active learning assignments. Partnership, 8. https://doi.org/10.21083/ partnership.v8i1.2499

Jaggars, S. S., \& Xu, D. (2016). How do online course design features influence student performance? Computers \& Education, 95, 270-284. https://doi.org/10.1016/j.compedu.2016.01.014

Janicki, T., \& Liegle, J. O. (2001). Development and evaluation of a framework for creating web-based learning modules: A pedagogical and systems perspective. Online Learning, 5(1), Article 1. https://doi. org/10.24059/olj.v5i1.1887

Jones, K. R. (2013). Developing and implementing a mandatory online student orientation. Online Learning, 17(1), Article 1. https://doi.org/10.24059/olj.v17i1.312

Joo, Y. J., Lim, K. Y., \& Kim, E. K. (2011). Online university students' satisfaction and persistence: Examining perceived level of presence, usefulness and ease of use as predictors in a structural model. Computers \& Education, 57(2), 1654-1664. https://doi.org/10.1016/j.compedu.2011.02.008

Karthik, B. S. S., Chandrasekhar, B. B., David, D. R., \& Kumar, D. A. K. (2019). Identification of instructional design strategies for an effective e-learning experience. The Qualitative Report, 24(7), 1537-1555.

Keller, J. M. (2008). First principles of motivation to learn and e3-learning. Distance Education, 29(2), 175-185. https://doi.org/10.1080/01587910802154970

Kim, C., \& Keller, J. M. (2008). Effects of motivational and volitional email messages (MVEM) with personal messages on undergraduate students' motivation, study habits and achievement. British Journal of Educational Technology, 39(1), 36-51. https://doi.org/10.1111/j.1467-8535.2007.00701.x

Korstange, R., Hall, J., Holcomb, J., \& Jackson, J. (2020). The online first-year experience: Defining and illustrating a new reality. Adult Learning, 31(3), 95-108. https://doi.org/10.1177/1045159519892680

Levy, Y. (2007). Comparing dropouts and persistence in e-learning courses. Computers \& Education, 48(2), 185-204. https://doi.org/10.1016/j.compedu.2004.12.004 
Lim, H., Lee, S.-G., \& Nam, K. (2007). Validating e-learning factors affecting training effectiveness. International Journal of Information Management, 27(1), 22-35. https://doi.org/10.1016/j.ijinfomgt.2006.08.002

Liu, J. C. (2019). Evaluating online learning orientation design with a readiness scale. Online Learning, 23(4), Article 4. https://doi.org/10.24059/olj.v23i4.2078

Long, L., Dubois, C., \& Faley, R. (2009). A case study analysis of factors that influence attrition rates in voluntary online training programs. International Journal on E-Learning, 8(3), 347-359. https://www.learntechlib. org/primary/p/26285/.

Marineo, F., \& Shi, Q. (2019). Supporting Student Success in the First-Year Experience: Library Instruction in the Learning Management System. Journal of Library \& Information Services in Distance Learning, 13(1-2), 40-55. https://doi.org/10.1080/1533290X.2018.1499235

Marks, R. B., Sibley, S. D., \& Arbaugh, J. B. (2005). A structural equation model of predictors for effective online learning. Journal of Management Education, 29(4), 531-563. https://doi.org/10.1177/1052562904271199

Mayer, R. (2017). Using multimedia for e-learning. Journal of Computer Assisted Learning, 33(5), 403-423. https://doi.org/10.1111/jcal.12197

Means, B., Toyama, Y., Murphy, R., \& Baki, M. (2013). The effectiveness of online and blended learning: A metaanalysis of the empirical literature. Teachers College Record, 115. https://www.sri.com/work/publications/ effectiveness-online-and-blended-learning-meta-analysis-empirical-literature

Montgomerie, K., Edwards, M., \& Thorn, K. (2016). Factors influencing online learning in an organisational context. Journal of Management Development, 35, 1313-1322. https://doi.org/10.1108/JMD-05-2016-0067

Moore, S. D., Sanchez, R. J., Inoue, A. B., Statham, R. D., Zelezny, L., \& Covino, W. A. (2014). Leveraging technology to alleviate student bottlenecks: The Self-Paced Online Tutorial-Writing (SPOT). The Journal of Continuing Higher Education, 62(1), 50-55. https://doi.org/10.1080/07377363.2014.872402

Mulvaney, M. (2020). Discussion groups and multi-formatted content delivery in an online module: Effect on students' self-efficacy. College Student Journal, 54(1), 88-105.

NODA. (2013). NODA General Survey [Unpublished raw data].

O'Connor, C., Sceiford, E., Wang, G., Foucar-Szocki, D., \& Griffin, O. (2003). Departure, abandonment, and dropout of e-learning: Dilemma and solutions. https://www.academia.edu/1217610/Departure_abandonment_and_ dropout_of_e-learning_Dilemma_and_solutions

Paechter, M., Maier, B., \& Macher, D. (2010). Students' expectations of, and experiences in e-learning: Their relation to learning achievements and course satisfaction. Computers \& Education, 54(1), 222-229. https:// doi.org/10.1016/j.compedu.2009.08.005

Peregrina-Kretz, D., Seifert, T., Arnold, C., \& Burrow, J. (2018). Finding their way in post-secondary education: The power of peers as connectors, coaches, co-constructors and copycats. Higher Education Research \& Development, 37(5), 1076-1090. https://doi.org/10.1080/07294360.2018.1471050

Reich, J., \& Ruipérez-Valiente, J. A. (2019). The MOOC pivot. Science, 363(6423), 130-131. https://doi. org/10.1126/science.aav7958

Ramage, T. (2002). The "no significant difference" phenomenon: A literature review. SPARK Scholarship at Parkland. https://spark.parkland.edu/ramage_pubs/1

Richardson, M. J., \& Tate, S. (2013). Improving the transition to university: Introducing student voices into the formal induction process for new geography undergraduates. Journal of Geography in Higher Education, 37(4), 611-618. https://doi.org/10.1080/03098265.2013.769092

Rodrigues, H., Almeida, F., Figueiredo, V., \& Lopes, S. L. (2019). Tracking e-learning through published papers: A systematic review. Computers \& Education, 136, 87-98. https://doi.org/10.1016/j.compedu.2019.03.007 
Singleton, K. K. (2019). Reimagining the community of inquiry model for a workplace learning setting: A program evaluation [Unpublished doctoral dissertation]. University of South Florida.

Strother, J. B. (2002). An assessment of the effectiveness of e-learning in corporate training programs. International Review of Research in Open and Distance Learning; Athabasca, 3(1).

Taylor, J. M. (2015). Innovative orientation leads to improved success in online courses. Online Learning, 19(4), Article 4. https://doi.org/10.24059/olj.v19i4.570

Watts, J. (2019). Assessing an online student orientation: Impacts on retention, satisfaction, and student learning. Technical Communication Quarterly, 28(3), 254-270. https://doi.org/10.1080/10572252.2019.16 07905

Weeks, T., \& Davis, J. P. (2017). Evaluating best practices for video tutorials: A case study. Journal of Library \& Information Services in Distance Learning, 11(1-2), 183-195. https://doi.org/10.1080/153329 0X.2016.1232048 